\title{
Inhibition of heme oxygenase-1 increases responsiveness of melanoma cells to ALA-based photodynamic therapy
}

\author{
JÜRGEN FRANK ${ }^{1}$, MOHAMMAD REZA LORNEJAD-SCHÄFER ${ }^{1}$, HARALD SCHÖFFL ${ }^{1}$, \\ ANDREA FLACCUS $^{2}$, CHRISTINE LAMBERT ${ }^{2}$ and HANS K. BIESALSKI ${ }^{2}$ \\ ${ }^{1}$ zet Life Science Laboratory Linz, Centre for Alternative and Complementary Methods to Animal Testing, 4020 Linz, Austria; \\ ${ }^{2}$ Institute of Biological Chemistry and Nutrition, University of Hohenheim, Garbenstr. 30, 70593 Stuttgart, Germany
}

Received June 27, 2007; Accepted August 13, 2007

\begin{abstract}
Based on the observation that 5-aminolevulinic acid (ALA) induces the expression of heme oxygenase-1 (HO-1) in cultured melanoma cells, the role of HO-1 on the effectiveness of 5-aminolevulinic acid-based photodynamic therapy (ALA-PDT) was examined. Transcriptional activation of the HO-1 gene is considered to be an adaptive response to oxidative and cellular stress and confers a protective capacity against cell and tissue injury, which could affect the responsiveness to ALA-PDT. A time-dependent accumulation $(0-16 \mathrm{~h})$ of protoporphyrin IX (PPIX) within melanoma cells was seen after incubation with ALA (0.5 mM ALA). Over the same time interval, a significant increase (up to 25 -fold) in HO-1 protein expression was observed. Thus, the production and degradation of PPIX (via heme by HO-1) were simultaneously enhanced, leading to a reduced intracellular concentration of the photodynamically active substance PPIX. Diminishing HO-1 activity by the HO-1 inhibitor tin protoporphyrin IX (SnPPIX) significantly enhanced the formation of PPIX up to 1.8 fold. A further strong increase in HO-1 protein expression (up to 128 -fold) was seen after ALA-PDT treatment. Induction of HO-1 is an essential step in the 'rescue response' of tumor cells. The pharmacological inhibition of HO-1 activity by SnPPIX leads to a considerable increase in the sensitivity of tumor cells to ALA-PDT treatment. At low radiation doses $\left(0.42 \mathrm{~J} / \mathrm{cm}^{2}\right)$, the percentages of death cells increased significantly from $7.3 \pm 1.3 \%$ to $43.7 \pm 6.4 \%$. This effect could be further intensified by cellular depletion of HO-1 mRNA by siRNA. The combination of pharmacological inactivation of HO-1 with gene silencing led to an increase in the death rate of up to $54.1 \pm 8.6 \%$. The results presented indicate that $\mathrm{HO}-1$ can play a protective role against ALA-PDT mediated cytotoxicity so that a specific
\end{abstract}

Correspondence to: Dr Jürgen Frank, zet Life Science Laboratory Linz, Scharitzerstr. 6-8, 4020 Linz, Austria

E-mail: j.frank@zet.or.at

Key words: heme oxygenase, photodynamic therapy, 5-aminolevulinic acid, reactive oxygen species, ALA-PDT, cancer inhibition of HO-1 activity and/or expression might be used to increase the efficacy of ALA-based photodynamic therapy.

\section{Introduction}

Photodynamic therapy (PDT) is widely used to treat preneoplastic skin lesions and non-melanoma skin tumors (1). PDT involves the activation of exogenously applied or endogenously formed photosensitizers by light to induce cell death via formation of singlet oxygen and other reactive oxygen species (ROS). These molecules can damage certain cell components (lipids, proteins, nucleic acids) by oxidative processes, resulting in cell death (2). In the present study, PDT was carried out using the natural porphyrin precursor 5-aminolevulinic acid (ALA), which is converted within cells, via the heme cycle, to the active photosensitizer protoporphyrin IX. In tumor cells, a preferential accumulation of this photosensitizer has been observed (3). Although numerous studies of topical photodynamic therapy (PDT) performed over the past decade indicate efficacy in nonmelanoma skin cancer and precursor lesions (4), the primary response rate for superficial basal cell carcinomas (BCC) or superficial squamous cell carcinomas upon ALA-PDT appears to be unsatisfactory (5), so that topical ALA-PDT alone appears to be a relatively poor treatment option for squamous cell carcinomas. Advanced treatment options are therefore needed to considerably improve the therapeutic effect of ALA-PDT in order to expand the application spectrum for this promising treatment modality.

One of the genes which have been discussed as being involved in the 'rescue response' of the tumor is heme oxygenase-1 (HO-1) (6,7). HO-1 is an inducible stress protein which confers cytoprotection against oxidative injury and cellular stress both in vitro and in vivo (8). In addition to its physiological role in heme degradation, HO- 1 influences a number of cellular processes including growth (9), inflammation (10) and apoptosis (6). In humans, two isoforms of heme oxygenase have been described: a constitutively expressed isoform, $\mathrm{HO}-2$, and an inducible isoform, $\mathrm{HO}-1$ $(11,12)$. Transcriptional activation of the HO-1 gene is considered to be an adaptive response aimed at protecting cells and tissues from injury in various pathological states 
(7). Correspondingly, local overexpression of HO-1 gene either by targeted gene transfer or by pharmacological modulation has been demonstrated to be protective against the deleterious effects of experimental injuries such as ischemia/ reperfusion injury or vascular disease and could potentially be exploited in future therapeutic applications (13-18). Conversely, deficient or diminished HO-1 expression in mammalian cells contributes to a reduced stress defense and facilitates cell death $(19,20)$. Berberat and colleagues demonstrated that gene silencing of HO- 1 by small interfering RNA transfection in pancreatic cancer cells made tumor cells significantly more sensitive to radiotherapy and chemotherapy (21). Recently, Nowis et al showed that transfection of tumor cells with the HO-1 gene resulted in protection of tumor cells against the effects of Photofrin-mediated PDT, whereas a blockade of its enzymatic activity with Zn(II)PPIX enabled tumor cells to survive PDT treatment (22). In our case, an unintended induction of HO-1 (up to 27-fold on protein level) was observed following tumor cell loading with 5-ALA, a precursor substance for photosensitizing porphyrins. In this context, an induction of HO-1 prior to PDT-treatment could potentially render tumor cells resistant to therapy, whereas a pharmacological inhibition of HO-1 activity or gene silencing of HO-1 by siRNA could enable an enhancement of the cytotoxic effects of ALA-PDT. Both of these possibilities were explored in this study with the aim of elucidating ways in which the effectiveness of topical ALA-PDT, which is currently being used for the treatment of dermato-oncologic conditions such as actinic keratoses, Bowen's disease, in-situ squamous cell carcinoma and basal cell carcinoma, might be improved.

\section{Materials and methods}

Statistical analysis. Results are expressed as means \pm SD unless stated otherwise. Differences between groups were assessed by the 2-tailed Wilcoxon test for unpaired samples. The significance level was set at $\alpha=5 \%$ for all comparisons.

Materials. All chemicals were obtained from Sigma (Deisenhofen, Germany) unless otherwise indicated. Cell culture materials were purchased from Biochrom (Berlin, Germany) or Greiner (Frickenhofen, Germany).

Cell culture. Experiments were performed using the metastatic human melanoma cell line WM451Lu which was kindly provided by Dr Birgit Schittek (Department of Dermatology, Eberhard-Karls-University, Tübingen, Germany). Cells grew in vitro in MCDB 153 medium (without phenol red) supplemented with $20 \%$ Leibowitz L15, $2 \%$ fetal bovine serum, $5 \mu \mathrm{g} / \mathrm{ml}$ insulin, $2 \mathrm{mM}$ L-glutamine, $50 \mu \mathrm{g} / \mathrm{ml}$ gentamycin at $37^{\circ} \mathrm{C}$ in a humidified $5 \% \quad \mathrm{CO}_{2}$ atmosphere. They were passaged twice weekly using $0.05 \%$ Trypsin, $0.02 \%$ EDTA.

Quantification of intracellular PPIX by FACS analysis. The extent of PPIX biosynthesis induced by ALA was determined by measuring the porphyrin fluorescence intensity in living cells. Cells were incubated in MCDB 153, 20\% Leibowitz L15, $5 \mu \mathrm{g} / \mathrm{ml}$ Insulin, $2 \mathrm{mM}$ L-glutamin, $50 \mu \mathrm{g} / \mathrm{ml}$ gentamycin without FCS and $0.5 \mathrm{mM}$ 5-ALA in the dark for 4, 8 and $16 \mathrm{~h}$. At selected times, cells were detached using trypsin and porphyrin fluorescence was analyzed by flow cytometry (Coulter, Hialeah, FL, USA; wavelengths: excitation $=488 \mathrm{~nm}$, emission $=620 \mathrm{~nm})$. Cellular fluorescence was quantified using the geometric means of data distributions $\left(\mathrm{G}_{\text {Mean }}\right)$. Non-treated melanoma cells served as controls. To prevent degradation of formed PPIX by HO-1, cells were incubated with the HO-1 inhibitor SnPPIX (Frontier Scientific, Logan, $\mathrm{UT}$ ) in a concentration range from $50 \mu \mathrm{M}$ to $1.6 \mathrm{mM}$.

Determination of HO-1 protein expression. The expression of HO-1 was assessed as described previously with minor modifications (23). Briefly, $5 \times 10^{6}$ melanoma cells were resuspended in $350 \mu \mathrm{l}$ of a hypotonic buffer (10 mM Tris$\mathrm{HCl}, \mathrm{pH} \mathrm{7.5,0.9 \%} \mathrm{NP-40,0.1 \%} \mathrm{SDS,} 1$ mM Pefabloc), incubated for $60 \mathrm{~min}$ on ice and then homogenized in a tissue grinder. The homogenate was centrifuged at $10,000 \mathrm{x} \mathrm{g}$ for $10 \mathrm{~min}$ at $4^{\circ} \mathrm{C}$. The amount of protein in each sample was measured using the Bio-Rad DC protein assay.

Equal protein amounts $(15 \mu \mathrm{g})$ were run on a $12 \%$ polyacrylamide gel and blotted onto PVDF membranes by semidry electroblotting. Membranes were stained with Ponceau S to verify equal protein loading per lane. Western blot detection: after blocking $(5 \%$ milk powder and $0.05 \%$ Tween-20 in TBS) the membranes for $1 \mathrm{~h}$, blots were probed for $1 \mathrm{~h}$ with primary antiserum (rabbit polyclonal anti-HO-1; StressGen Biotechnologies, Victoria, BC, Canada) and rinsed three times with TBST. The membranes were then probed with horseradish peroxidase-conjugated secondary antibody (goat anti-rabbit IgG horseradish peroxidase linked; Dako, Hamburg, Germany) for $1 \mathrm{~h}$. After three rinses in TBST, bound antibodies were visualized using chemiluminescence detection (LumiGLO ${ }^{\mathrm{TM}}$; Cell signaling, Beverly, MA) on autoradiographic film. HO-1 expression was quantified by densitometric scanning of the autoradiographic film with the Herolab E.A.S.Y. enhanced analysis system (Herolab, Wiesloch, Germany). To correct for differences in gel loading and blotting, integrated optical densities were normalised to $ß$-actin (goat polyclonal anti-actin antibody; Santa Cruz Biotechnologies, Santa Cruz, CA), obtained on the same blot.

Determination of HO-1 mRNA expression by real-time PCR. The mRNA expression of HO-1 was measured quantitatively by real-time RT-PCR (iCycler, Bio-Rad, Munich, Germany). 18s rRNA expression served as a control for the cDNA amount. Total RNA isolation was performed using the RNeasy mini kit (Qiagen, Hilden, Germany). Total RNA (1 $\mu \mathrm{g})$ was transcribed into cDNA using I Script cDNA Synthesis Kit (Bio-Rad, Munich, Germany) and oligo dT-primers (end volume: $20 \mu \mathrm{l}$ ) according to the manufacturer's instructions. The following primers were used: HO-1: 5'-GGT GAT AGA AGA GGC CAA GAC-3' and 5'-GCA GAA TCT TGC ACT TTG TTG-3'. 18s rRNA: 5'-ACA CGG ACA GGA TTG ACA GA-3' and 5'-GGA CAT CTA AGG GCA TCA CA-3'. Real-time RT-PCR was performed using iQ SYBR Green Supermix (Bio-Rad) according to the manufacturer's instructions. Briefly, $1 \mu 1$ of cDNA was added to the master $\operatorname{mix}[12.5 \mu 12 x$ iQ SYBR Green Supermix, $0.25 \mu 1$ of each primer $(25 \mathrm{pmol} / \mu 1), 11 \mu 1 \mathrm{RNAse}$-free water]. A calibration 
curve was run in parallel and in duplicate with each analysis, using PCR fragments of the target cDNA in a concentration of $10^{1}-10^{7}$ copies per sample. Negative water blanks were included in each analysis. A 3-min denaturation step at $95^{\circ} \mathrm{C}$ activated the Taq polymerase, which was followed by 30 or 40 PCR cycles, in accordance with the following protocol: denaturation at $95^{\circ} \mathrm{C}(30 \mathrm{sec})$, annealing at $57^{\circ} \mathrm{C}$ up to $61^{\circ} \mathrm{C}$ (depending on the primers used; $30 \mathrm{sec}$ ), and elongation at $72^{\circ} \mathrm{C}(30 \mathrm{sec})$. At the end of the PCR, a melting curve analysis was performed by gradually increasing the temperature to $95^{\circ} \mathrm{C}$. This was to detect possible formation of primerdimers. Data acquisition was performed during the elongation step. After PCR completion, the SYBR Green fluorescent signal was transformed into a relative number of copies of target molecules. Differences in cDNA amount were equalized by expression of the housekeeping gene $18 \mathrm{~s}$ rRNA.

HO-1 specific siRNA. HO-1 siRNA was purchased from Qiagen (cat.\#SI00033103) sense r(GGC AAU GGC CUA AAC UUC A) dT dT antisense r(UGA AGU UUA GGC CAU UGC C) dT dG. The sequence sense UUC UCC GAA CGU GUC ACG UdT dT and antisense ACG UGA CAC GUU CGG AGA AdT dT was used as the scrambled siRNA control (Qiagen cat.\#1022076) and does not match with any mammalian sequence currently available in online databases.

Transfection of the human melanoma cell line WM451Lu with siRNA. Transfection of human melanoma cells by Magnetofection (Acris, Hiddenhausen, Germany) was optimized first by using a negative control siRNA Alexa Fluor 488 label provided by Qiagen (Catalog No. 1022563) for transfection monitoring. Cells were transfected with various concentrations of negative control siRNA (1-100 nmol/l) and different amounts of Magnetofection reagent for $24 \mathrm{~h}$ in cell culture medium containing 10\% FCS. Transfection efficiency was evaluated by fluorescence microscopy. Optimal transfection efficiency was obtained with $100 \mathrm{nmol} / \mathrm{l}$ siRNA and $1 \mu 1$ Magnetofection reagent (PolyMag). These conditions were used for the subsequent siRNA transfection experiments. Briefly, cells were seeded one day prior to transfection at a cell density of $1 \times 10^{5}$ cells $/ \mathrm{cm}^{2}$ so that cells were $70-80 \%$ confluent at the time of transfection. One hour prior to transfection, cell medium was replaced with $3.8 \mathrm{ml}$ fresh-culture medium (19.6 $\mathrm{cm}^{2}$ cell culture dish). Paramagnetic particles (8 $\mu 1$ ) (PolyMag) were given to a microtube. Twenty $\mu 1$ siRNA $(20 \mu \mathrm{M})$ were diluted in $180 \mu$ l OPTIMEM (Gibco), transferred into the PolyMag solution and mixed by vigorous pipetting. After $30 \mathrm{~min}$ of incubation at room temperature, the whole solution was added to the cells. The culture plate was placed upon a magnetic plate (Acris) and incubated for $10 \mathrm{~min}$ at $37^{\circ} \mathrm{C}$. Subsequently, the culture dish was transferred to the incubator at $37^{\circ} \mathrm{C}$ in a humidified $5 \% \mathrm{CO}_{2}$ atmosphere. Eight hours later, culture medium was replaced with $0.5 \mathrm{mM}$ ALA in serum-free culture medium. Sixteen hours later, cells were irradiated and RNA was isolated $24 \mathrm{~h}$ after irradiation.

Photodynamic treatment. Melanoma cells were seeded at a density of $1 \times 10^{6}$ cells in MCDB 153/20\% Leibowitz L15/2\% FCS $/ 5 \mu \mathrm{g} / \mathrm{ml}$ insulin $/ 2 \mathrm{mM}$ L-glutamine $/ 50 \mu \mathrm{g} / \mathrm{ml}$ gentamycin without phenol red in small cell culture petri dishes $\left(19.6 \mathrm{~cm}^{2}\right)$. After reaching confluence, cells were incubated for $16 \mathrm{~h}$ in FCS-free medium with $0.5 \mathrm{mM}$ ALA in the dark at $37^{\circ} \mathrm{C}$. Thereafter, medium was replaced by fresh phenol red-free MCDB 153/20\% Leibowitz L15/5 $\mu \mathrm{g} / \mathrm{ml}$ insulin/2 mM L-glutamine $/ 50 \mu \mathrm{g} / \mathrm{ml}$ gentamycin medium supplemented with $2 \%$ FCS and cells were illuminated with a light intensity of $70 \mathrm{~mW} / \mathrm{cm}^{2}$ and light doses of between $0.42 \mathrm{~J} / \mathrm{cm}^{2}$ and $2.54 \mathrm{~J} / \mathrm{cm}^{2}$. The radiation source is a halogen lamp emitting wavelengths over the range 420-1400 nm (hydrosun ${ }^{\circledR}$ PIRAradiator, Hydrosun Medizintechnik GmbH, Muellheim, Germany). By using a band-pass filter, cells were illuminated with a wavelength range encompassing the activation wavelengths for PPIX (420-800 nm). Light dosimetry was performed using a calibrated radiometer/photometer (IL1400A, International Light, Newburyport, MA).

Assessment of cell viability with 7-AAD. Staining cells with 7-aminoactinomycin D is a well-described method used to identify living and dead cells in a given cell population $(24,25)$. Melanoma cells were washed in antibody buffer (10 mM HEPES, pH 7.4, $140 \mathrm{mM} \mathrm{NaCl}, 2.4 \mathrm{mM} \mathrm{CaCl}_{2}$ ) and stained with $22 \mu \mathrm{M}$ 7-aminoactinomycin D (7-AAD) for $20 \mathrm{~min}$ at $4^{\circ} \mathrm{C}$ in the dark. Thereafter, cells were washed once and resuspended in antibody buffer. Flow cytometric analysis must be performed within $1 \mathrm{~h}$ (FSC vs. fluorescence at $675 \mathrm{~nm}$ ). Living and dead cells can be distinguished by FACS-analysis on the basis of their 7-AAD fluorescence.

\section{Results}

Porphyrin biosynthesis induced by 5-ALA. PPIX accumulation following incubation with 5-ALA was assessed over time (Fig. 1A). A time-dependent increase (4-16 h) in intracellular PPIX was seen in melanoma cells incubated in the presence of $0.5 \mathrm{mM}$ ALA with the later times showing the greatest concentrations. Shortly after removal of ALA (16-h value), the intracellular PPIX concentration returned to control levels (Fig. 1A, washout phase). As seen in Fig. 1B, the accumulation of PPIX was found to be relatively specific to cancer cells. In comparison with normal human fibroblasts (HFP-4), 5-ALA administration to the cancer cell lines investigated resulted in a much greater increase in PPIX (WM451 9.8-fold, DU145 28.7-fold, WM115 13.2-fold, HT-29 9.8-fold, MonoMac 16-fold).

Induction of $\mathrm{HO}-1$ by 5-ALA. An increase in HO-1 protein expression in melanoma cells (WM451) was evident immediately after loading of cells with 5-ALA. Already $4 \mathrm{~h}$ after ALA-treatment, an 11-fold increase in HO-1 protein expression was detected in comparison to untreated control cells (Fig. 2A and B). The induction of HO-1 protein expression was highest (27-fold) $8 \mathrm{~h}$ after cell incubation with 5-ALA and did not increase further over time (Fig. 2B). This would suggest that both production and degradation of PPIX (via heme by HO-1) were simultaneously stimulated. Cells loaded for $16 \mathrm{~h}$ with 5-ALA and subsequently incubated in medium without 5-ALA showed a time-dependent decrease in $\mathrm{HO}-1$ protein expression (Fig. 2B, washout phase). In addition, a significant increase in the intracellular PPIX 


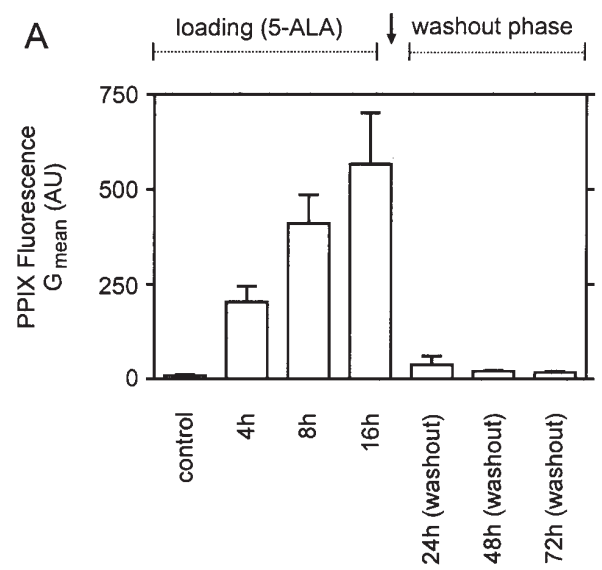

B

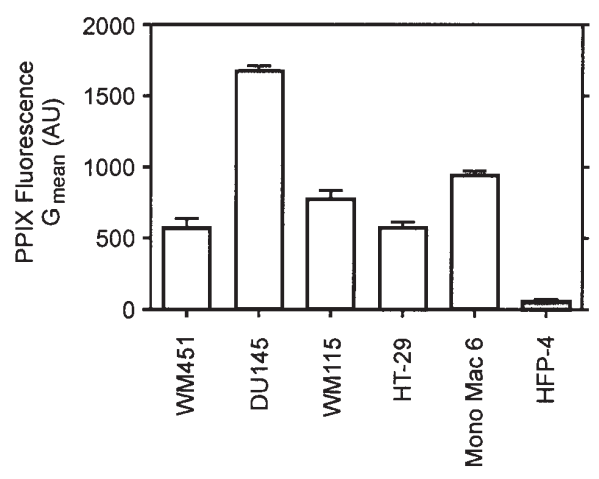

Figure 1. (A) Levels of intracellular PPIX measured in cultured melanoma cells over time in the presence and absence (washout phase) of $0.5 \mathrm{mM}$ 5-ALA. Quantitative analyses were performed on geometric means $\left(\mathrm{G}_{\text {means }}\right)$ of the data distributions. (B) Generation of PPIX in different human cancer cell lines in comparison to normal human fibroblasts (HFP-4). Normal cells accumulate considerably smaller amounts of PPIX in the presences of $0.5 \mathrm{mM}$ 5-ALA. Values at $16 \mathrm{~h}$ are shown. Results represent means $\pm \mathrm{SD}$ of at least four independent experiments.

concentration could be achieved by reducing HO-1 activity through the HO-1 inhibitor SnPPIX. As shown in Fig. 3, the addition of SnPPIX during the incubation step with 5-ALA resulted in an increased intracellular PPIX concentration presumably resulting from a reduced degradation of PPIX via heme by HO-1. The highest SnPPIX concentration which could be used resulted in a 1.8 -fold increase in PPIX. SnPPIX concentrations $>400 \mu \mathrm{M}$ caused cytotoxic side effects and could not be assessed (data not shown). A further strong induction of HO-1 protein expression was seen upon photodynamic treatment (Fig. 2C). The maximum level of $\mathrm{HO}-1$ protein expression was reached $48 \mathrm{~h}$ after irradiation of melanoma cells with $2.52 \mathrm{~J} / \mathrm{cm}^{2}$ (128-fold increase in comparison to untreated control cells). The increase of HO-1 was transient and declined after this time point. Activation of HO-1 has been considered to be an adaptive cellular defense mechanism which provides cytoprotection in various in vitro and in vivo systems. Therefore, specific inhibition of HO-1 expression and/or HO-1 activity may provide a new option to improve the efficiency of photodynamic therapy, particularly when 5-ALA is used.

Reduction of HO-1 activity potentiates ALA-PDT induced cell death. In order to determine whether the induced high
A

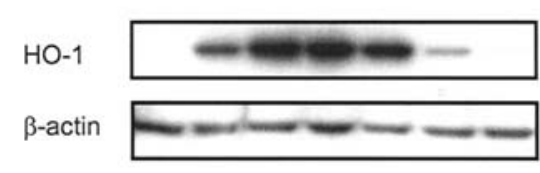

B

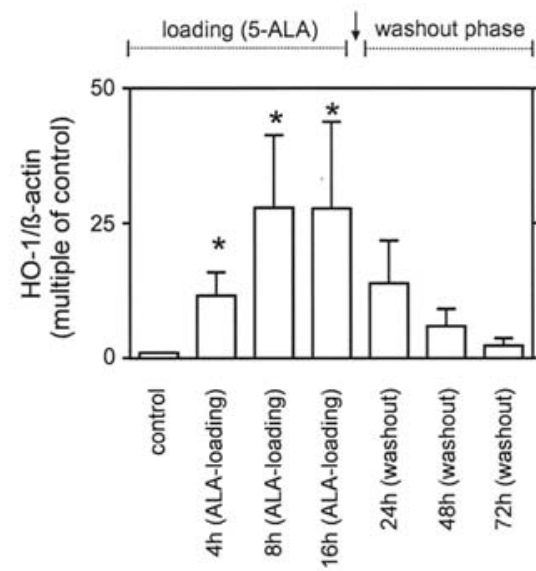

C

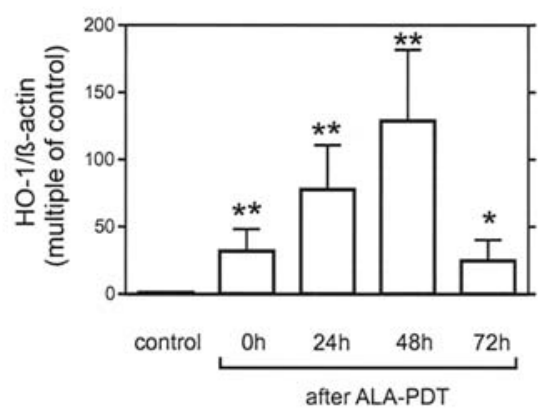

Figure 2. Effect of ALA and ALA-PDT on HO-1 protein expression in melanoma cells. (A) A representative Western blot for the increase of HO-1 by 5-ALA is shown. (B and C) Show densitometrical analysis of Western blots expressed relative to values in control cells, which were set to $100 \%$. (B) An increase in HO-1 protein expression in melanoma cells was evident immediately after loading the cells with 5-ALA $(0.5 \mathrm{mM})$. Already $4 \mathrm{~h}$ after 5-ALA-treatment an 11-fold increase in HO-1 protein expression was detected in comparison to untreated control cells. After $8 \mathrm{~h}$ the maximum accumulation of HO-1 protein due to 5-ALA treatment was achieved (27-fold) and reached a plateau. Cells, treated for $16 \mathrm{~h}$ with 5-ALA and subsequently incubated in medium without 5-ALA showed a time dependent decrease in HO-1 protein expression (washout phase). (C) A further strong induction of HO-1 protein expression was seen upon photodynamic treatment. The maximum level of HO-1 protein expression was reached $48 \mathrm{~h}$ after irradiation of melanoma cells with $2.52 \mathrm{~J} / \mathrm{cm}^{2}$ (128-fold increase in comparison to untreated control cells). The increase of HO-1 was transient and declined after this time point. Results represent means \pm SEM of at least four independent experiments. ${ }^{*} \mathrm{p}<0.05$ vs. control and ${ }^{* *} \mathrm{p}<0.005$ vs. control.

expression levels of HO-1 upon ALA loading and ALAbased photodynamic therapy are responsible for rescuing melanoma cells from ALA-PDT-induced cell death, the HO-1 activity was suppressed by the HO-1 inhibitor SnPPIX and cell viability subsequently evaluated. As seen in Fig. 4, the inhibition of HO-1 activity by $400 \mu \mathrm{M}$ SnPPIX resulted in a greater sensitivity of melanoma cells to ALA-PDT treatment. At low radiation doses $\left(0.42 \mathrm{~J} / \mathrm{cm}^{2}\right)$ the death rate upon ALA-PDT treatment increased significantly from $7.3 \pm 1.3 \%$ to $43.7 \pm 6.4 \%$. A phototoxic effect of SnPPIX was not observed under these conditions. The increase of dead cells may prove to be meaningful in tumor areas in which the radiation damage upon treatment is inadequate due to low 


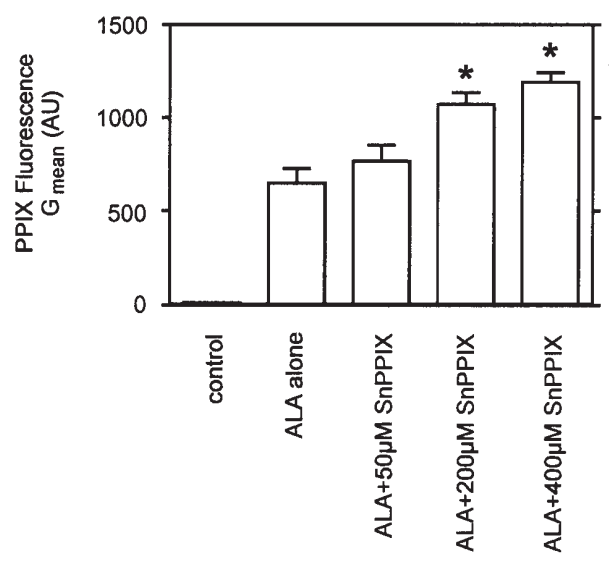

Figure 3. Effect of pharmacological inhibition of HO-1 activity by SnPPIX. Cells were incubated for $16 \mathrm{~h}$ with 5-ALA with or without the presence of different concentrations of the HO-1 inhibitor SnPPIX. Inhibition of HO-1 activity significantly enhanced the accumulation of PPIX within melanoma cells up to 1.8-fold. The effect was dependent on the concentration of the inhibitor used. Results represent means \pm SEM of four independent experiments. ${ }^{*} \mathrm{p}<0.05$ vs. ALA alone.

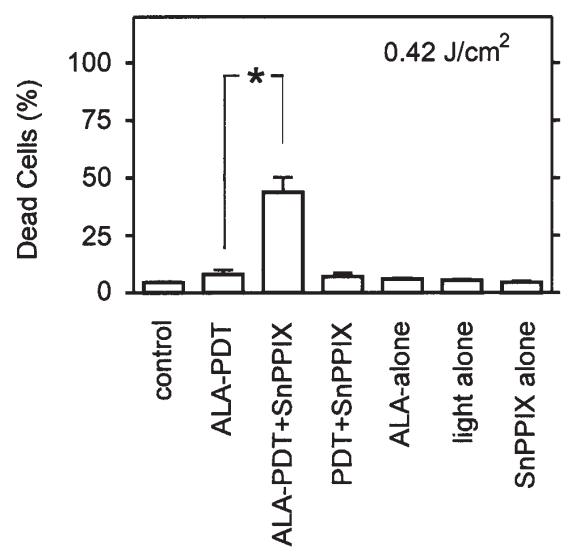

Figure 4. Effect of HO-1 inhibition on cell survival. The inhibition of HO-1 activity by SnPPIX made tumor cells considerably more sensitive to ALAPDT treatment. Cells were loaded for $16 \mathrm{~h}$ with $0.5 \mathrm{mM} \mathrm{5-ALA}$ in the presence of $400 \mu \mathrm{M}$ SnPPIX. Thereafter, medium was replaced and cells were irradiated. Forty-eight hours after PDT treatment, cells were harvested and analyzed for cell survival. Data refer to means \pm SEM of at least five independent experiments. " $\mathrm{p}<0.01$.

PPIX synthesis or light intensity and may lead to a reduction in the recurrence-rate of PDT-treated tumors. As a consequence of these findings, a further set of experiments was carried out to examine the effects of a specific inhibition of HO-1 mRNA by siRNA.

Inhibition of HO-1 mRNA expression by siRNA. As seen earlier, on the basis of protein level (Fig. 2A and B), the incubation of melanoma cells with 5-ALA for $16 \mathrm{~h}$ resulted in a significant increase in HO-1 mRNA expression (Fig. 5B). This increase could be reduced from 8.2- to 2.9-fold by gene silencing with a specific HO-1 siRNA probe. This means a reduction of $\sim 71 \%$ on the mRNA level. Transfection of the cells with scrambled siRNA did not result in a reduction of HO-1 mRNA (mock control). The specific reduction of HO-1 mRNA by siRNA also resulted in a down-regulation of $\mathrm{HO}-1$
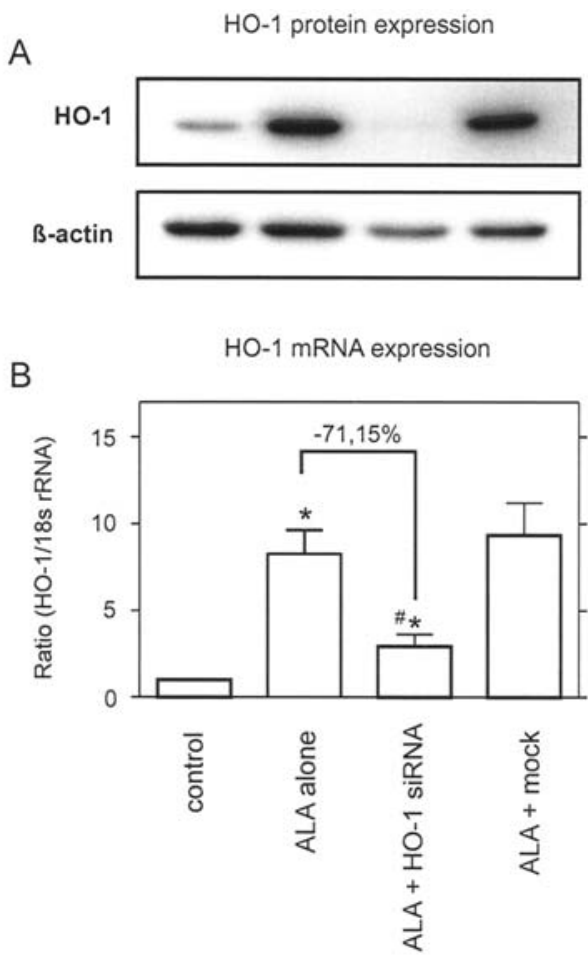

Figure 5. Reduction of HO-1 mRNA expression by siRNA. Gene silencing of HO-1 mRNA resulted in a decreased HO-1 mRNA (B) and HO-1 protein (A) expression. For HO-1 protein expression a representative Western blot is shown. Results represent means \pm SEM of four independent experiments. Transfection with HO-1 siRNA was undertaken $8 \mathrm{~h}$ before loading the cells for $16 \mathrm{~h}$ with $0.5 \mathrm{mM}$ 5-ALA. Twenty-four hours after ALA treatment, cells were harvested and examined for HO-1 mRNA and HO-1 protein expression by qPCR and Western blot analysis respectively. ${ }^{*} \mathrm{p}<0.001 \mathrm{vs}$. control and ${ }^{\# *} \mathrm{p}<0.001$ vs. ALA alone.

protein expression (Fig. 5A). As was the case with mRNA level, mock transfection with scrambled siRNA had no effect on HO-1 protein expression (Fig. 5A).

Gene silencing of HO-1 mRNA in combination with inhibition of $\mathrm{HO}-1$ activity. In a further set of experiments, specific inhibition of HO-1 mRNA by siRNA in combination with pharmacological inhibition of HO-1 activity by SnPPIX was used to further improve ALA-PDT treatment. Under conditions where radiation damage is low $\left(0.42 \mathrm{~J} / \mathrm{cm}^{2}\right) \mathrm{HO}-1$ gene silencing increased the percentages of death cells from $7.3 \pm 1.0 \%$ to $21.8 \pm 4.3 \%$. Diminishing of $\mathrm{HO}-1$ activity by SnPPIX resulted in an increase of the death rate from $7.3 \% \pm 1.0 \%$ to $43.7 \pm 6.4 \%$. The combination of both methods further increased the death rate up to $54.1 \pm 8.6 \%$. Our results clearly demonstrate that specific inhibition of HO-1 activity and/or expression might be a useful way to increase the effectiveness of ALA-based photodynamic therapy, particularly under circumstances where radiation damage upon treatment is inadequate due to low light intensity.

\section{Discussion}

Aminolevulinic acid is a prodrug that is metabolized intracellularly within the heme synthesis pathway to form the intermediate substance protoporphyrin IX (PPIX), a photosensitive molecule, which when activated by light can result 
in the formation of cytotoxic reactive oxygen species and free radicals (1). ALA-PDT is currently being clinically applied for treatment of a range of malignant and non-malignant diseases (26). At the same time however, PDT is capable of causing the activation of signalling pathways involved in adaptive responses that may enable cancer cells to repair cellular damage and thus to survive treatment (27). An understanding of the molecular events contributing to PDT-induced apoptosis and cancer cell evasion of apoptotic death may contribute to the development of more sophisticated approaches to drug design and therapy. Transcriptional activation of the HO-1 gene (hmox 1 ) is considered to be an adaptive response to oxidative and cellular stress and confers a protective capacity to cultured cells as well as to cells in several in vivo animal models (reviewed in ref. 28). The HO-1 gene is induced by agents and chemicals that produce an oxidative cellular stress involving the generation of reactive oxygen species. Photodynamic therapy generates a similar stress response and increased expression of HO-1 was observed some years ago following photodynamic stress with Photofrin II (29). Fifteen years later, Nowis et al (22) demonstrated that overexpression of HO-1 protects tumor cells against photodynamic therapy with Photofrin. In the present study, 5-aminolevulinic acid (ALA) was used as a prodrug to form the photosensitizing molecule PPIX. 5-ALAmediated photosensitization is one of the fastest developing areas in the field of PDT and many clinical ALA-PDT applications for malignant and non-malignant diseases are currently in use. Following administration of exogenous ALA, the endogenous photosensitizer PPIX accumulates in malignant cells (Fig. 1). Simultaneously, the expression of HO-1 was found to increase up to 25 -fold at the protein level (Fig. 2B). Heme precursors such as 5-ALA or PPIX may generate reactive oxygen species (ROS) from autoxidation (30) which may be responsible for the induction of the HO-1 response in the run-up of PDT treatment. PDT treatment was seen to result in an increased formation of ROS and a further enhancement of HO-1 induction (Fig. 2C). HO-1 catalyses the first and rate-limiting step in the oxidative degradation of heme to form the open-chain tetrapyrrole ring structure yielding free iron $\left(\mathrm{Fe}^{2+}\right)$, carbon monoxide $(\mathrm{CO})$ and biliverdin, which is subsequently converted to bilirubin by biliverdin-reductase $(31,32)$. Each of these products has been found to play a unique protective role in different disease models (28). PPIX is not a substrate for HO-1. Instead it must be converted to heme before it can be metabolized. Evaluation of PPIX accumulation by flow cytometry showed that in comparison to normal skin fibroblasts all cancer cell lines examined accumulate PPIX at higher levels (Fig. 1B). Normally, heme can be synthesized in virtually all tissues, but the principal sites of synthesis are erythroid cells and hepatocytes. In hepatocytes (and many other cells), heme is required for incorporation into the cytochromes. In erythroid cells, all of the heme is synthesized for incorporation into hemoglobin and occurs only upon differentiation when synthesis of hemoglobin proceeds. Control has been shown to be exerted through ferrochelatase and porphobilinogen deaminase. Porphobilinogen deaminase (PBGD) is ratelimiting in PPIX formation whereas ferrochelatase converts PPIX into heme by chelation of ferrous iron into PPIX.

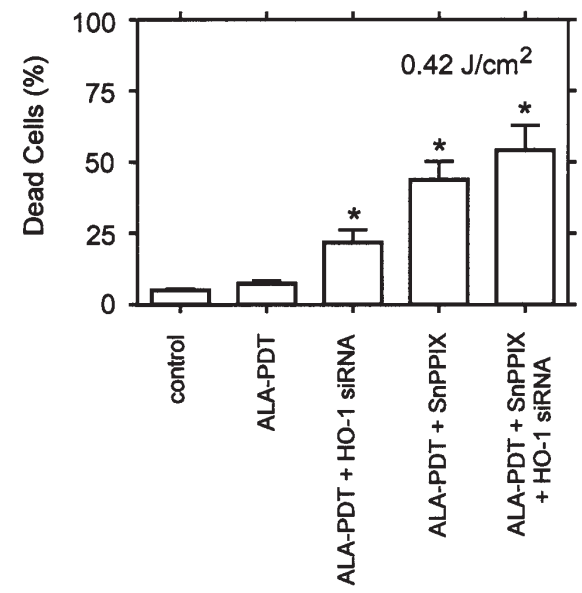

Figure 6. Effect of pharmacological inhibition of HO-1 by SnPPIX in combination with HO-1 gene silencing by siRNA. Transfection with HO-1 siRNA was undertaken $8 \mathrm{~h}$ before loading the cells for $16 \mathrm{~h}$ with $0.5 \mathrm{mM}$ 5 -ALA with or without the presence of $400 \mu \mathrm{M}$ SnPPIX. Thereafter, medium was replaced and cells were irradiated. Forty-eight hours after PDT treatment, cells were harvested and analyzed for cell survival. Data refer to means \pm SEM of at least four independent experiments. ${ }^{*} \mathrm{p}<0.01$ vs. ALAPDT.

In most tumors, a tumor-preferential PPIX accumulation is strongly influenced by the intracellular concentration of PPIX-converting ferrochelatase and augmented uptake of 5-ALA (33). Nevertheless, the considerable amounts of HO-1 formed during cell loading with 5-ALA will result in the immediate metabolism of all heme being formed by ferrochelatase. This may result in a shift of the enzymatic reaction towards heme formation from PPIX. Therefore, an overexpression of HO-1 in the run-up to PDT treatment may result in a decreased intracellular PPIX concentration since production and 'degradation' of PPIX were simultaneously promoted. When HO-1 activity was pharmacologically inhibited by SnPPIX, a clear increase (up to 1.8 -fold) in PPIX formation was observed (Fig. 3). This finding supports the notion that in the presence of excessive amounts of HO-1, more heme is formed from PPIX and immediately degraded by $\mathrm{HO}-1$.

A growing amount of evidence points to the critical role of HO-1 in cytoprotection and further diverse biological functions $(28,34)$. Induction of HO-1 by various chemical inducers that are primarily cell stress inducers or by HO-1 gene transfection confers a protective capacity to cultured cells as well as to cells in several in vivo animal models (6). In addition, HO-1-deficient mice exhibit a significant increase in susceptibility to tissue injury (35). In the present study, the inhibition of HO-1 activity and/or mRNA expression resulted in a significant increase in ALA-PDT treatment efficiency (Fig. 6) especially when low radiation doses were used. Normally, tumor regions containing the highest photosensitizer concentrations and receiving optimum light fluence undergo high rates of cell death by necrosis and apoptosis. Due to limited light penetration through tissues, the antitumor effects of PDT are limited to just a few centimeters. In deeper tumor layers suboptimal conditions may be confronted with the tumor cells receiving smaller light doses while at the same time tumor hypoxia may limit 
the amount of ROS formed so that only sublethal tumor cell damage can be achieved. The surviving cells might be responsible for tumor relapse rendering the treatment less effective. Under such circumstances, the inhibition of HO- 1 in the run-up to ALA-PDT treatment might be an extremely effective way of increasing cellular damage. Thus, by optimising the treatment modalities for ALA-PDT an enhanced efficacy might be reached. Furthermore, the inhibition of HO-1 activity and or expression has been demonstrated to potentiate antitumor activity of other antitumor treatments that relay on the generation of oxidative stress, including radiotherapy and chemotherapy $(6,21)$. High HO-1 levels in tumor cells may, at least partly, be responsible for their resistance to anticancer treatment. Therefore, specific inhibition of HO-1 activity and or expression in combination with conventional radiotherapy and chemotherapy may be a new option to enhance anticancer treatment efficacy.

\section{Acknowledgements}

The authors thank Dr habil. Debra Kelleher (Institute of Physiology and Pathophysiology, University of Mainz, Germany) for her expert assistance and critical reading of the manuscript.

\section{References}

1. Gupta AK and Ryder JE: Photodynamic therapy and topical aminolevulinic acid: an overview. Am J Clin Dermatol 4: 699-708, 2003.

2. Weishaupt KR, Gomer CJ and Dougherty TJ: Identification of singlet oxygen as the cytotoxic agent in photoinactivation of a murine tumor. Cancer Res 36: 2326-2329, 1976.

3. Henderson BW and Dougherty TJ: How does photodynamic therapy work? Photochem Photobiol 55: 145-157, 1992.

4. Morton CA, Brown SB, Collins S, et al: Guidelines for topical photodynamic therapy: report of a workshop of the British Photodermatology Group. Br J Dermatol 146: 552-567, 2002.

5. Fink-Puches R, Soyer HP, Hofer A, Kerl H and Wolf P: Longterm follow-up and histological changes of superficial nonmelanoma skin cancers treated with topical delta-aminolevulinic acid photodynamic therapy. Arch Dermatol 134: 821-826, 1998.

6. Fang J, Akaike $\mathrm{T}$ and Maeda $\mathrm{H}$ : Antiapoptotic role of heme oxygenase $(\mathrm{HO})$ and the potential of $\mathrm{HO}$ as a target in anticancer treatment. Apoptosis 9: 27-35, 2004.

7. Prawan A, Kundu JK and Surh AJ: Molecular basis of heme oxygenase-1 induction: implications for chemoprevention and chemoprotection. Antioxid Redox Signal 7: 1688-1703, 2005.

8. Bach FH: Heme oxygenase-1 as a protective gene. Wien Klin Wochenschr 114 (Suppl 4): 1-3, 2002.

9. Durante W: Heme oxygenase- 1 in growth control and its clinical application to vascular disease. J Cell Physiol 195: 373-382, 2003.

10. Alcaraz MJ, Fernandez P and Guillen MI: Anti-inflammatory actions of the heme oxygenase-1 pathway. Curr Pharm Des 9: 2541-2551, 2003.

11. Trakshel GM and Maines MD: Detection of two heme oxygenase isoforms in the human testis. Biochem Biophys Res Commun 154: 285-291, 1988.

12. McCoubrey WK Jr, Huang TJ and Maines MD: Isolation and characterization of a cDNA from the rat brain that encodes hemoprotein heme oxygenase-3. Eur J Biochem 247: 725-732, 1997.

13. Tsuchihashi S, Fondevila C and Kupiec-Weglinski JW: Heme oxygenase system in ischemia and reperfusion injury. Ann Transplant 9: 84-87, 2004.

14. Perrella MA and Yet SF: Role of heme oxygenase-1 in cardiovascular function. Curr Pharm Des 9: 2479-2487, 2003.
15. Katori M, Busuttil RW and Kupiec-Weglinski JW: Heme oxygenase-1 system in organ transplantation. Transplantation 74: 905-912, 2002.

16. Immenschuh S and Ramadori G: Gene regulation of heme oxygenase- 1 as a therapeutic target. Biochem Pharmacol 60: 1121-1128, 2000.

17. Jazwa A, Loboda A, Golda S, et al: Effect of heme and heme oxygenase-1 on vascular endothelial growth factor synthesis and angiogenic potency of human keratinocytes. Free Radic Biol Med 40: 1250-1263, 2006.

18. Nakamichi I, Habtezion A, Zhong B, Contag CH, Butcher EC and Omary MB: Hemin-activated macrophages home to the pancreas and protect from acute pancreatitis via heme oxygenase-1 induction. J Clin Invest 115: 3007-3014, 2005.

19. Poss KD and Tonegawa S: Reduced stress defense in heme oxygenase 1-deficient cells. Proc Natl Acad Sci USA 94: 10925-10930, 1997.

20. Malaguarnera L, Quan S, Pilastro MR, Abraham NG and Kappas A: Diminished heme oxygenase potentiates cell death: pyrrolidinedithiocarbamate mediates oxidative stress. Exp Biol Med 228: 459-465, 2003.

21. Berberat PO, Dambrauskas Z, Gulbinas A, et al: Inhibition of heme oxygenase- 1 increases responsiveness of pancreatic cancer cells to anticancer treatment. Clin Cancer Res 11: 3790-3798, 2005.

22. Nowis D, Legat M, Grzela T, et al: Heme oxygenase-1 protects tumor cells against photodynamic therapy-mediated cytotoxicity. Oncogene 25: 3365-3374, 2006.

23. Frank J, Lambert C, Biesalski HK, Thews O, Vaupel P and Kelleher DK: Intensified oxidative and nitrosative stress following combined ALA-based photodynamic therapy and local hyperthermia in rat tumors. Int J Cancer 107: 941-948, 2003.

24. Philpott NJ, Turner AJ, Scopes J, et al: The use of 7-amino actinomycin D in identifying apoptosis: simplicity of use and broad spectrum of application compared with other techniques. Blood 87: 2244-2251, 1996.

25. Frank J, Flaccus A, Schwarz C, Lambert C and Biesalski HK: Ascorbic acid suppresses cell death in rat DS-sarcoma cancer cells induced by 5-aminolevulinic acid-based photodynamic therapy. Free Radic Biol Med 40: 827-836, 2006.

26. Fukuda H, Casas A and Batlle A: Aminolevulinic acid: from its unique biological function to its star role in photodynamic therapy. Int J Biochem Cell Biol 37: 272-276, 2005.

27. Almeida RD, Manadas BJ, Carvalho AP and Duarte CB: Intracellular signaling mechanisms in photodynamic therapy. Biochim Biophys Acta 1704: 59-86, 2004

28. Ryter SW, Alam J and Choi AM: Heme oxygenase-1/carbon monoxide: from basic science to therapeutic applications. Physiol Rev 86: 583-650, 2006.

29. Gomer CJ, Luna M, Ferrario A and Rucker N: Increased transcription and translation of heme oxygenase in Chinese hamster fibroblasts following photodynamic stress or Photofrin II incubation. Photochem Photobiol 53: 275-279, 1991.

30. Ryter SW and Tyrrell RM: The heme synthesis and degradation pathways: role in oxidant sensitivity. Heme oxygenase has both pro- and antioxidant properties. Free Radic Biol Med 28: 289-309, 2000

31. Tenhunen R, Ross ME, Marver HS and Schmid R: Reduced nicotinamide-adenine dinucleotide phosphate dependent biliverdin reductase: partial purification and characterization. Biochemistry 9: 298-303, 1970.

32. Tenhunen R, Marver HS and Schmid R: Microsomal heme oxygenase. Characterization of the enzyme. J Biol Chem 244: 6388-6394, 1969

33. Ohgari Y, Nakayasu Y, Kitajima S, et al: Mechanisms involved in delta-aminolevulinic acid (ALA)-induced photosensitivity of tumor cells: relation of ferrochelatase and uptake of ALA to the accumulation of protoporphyrin. Biochem Pharmacol 71: 42-49, 2005

34. Kim HP, Ryter SW and Choi AM: $\mathrm{CO}$ as a cellular signaling molecule. Annu Rev Pharmacol Toxicol 46: 411-449, 2006.

35. Poss KD and Tonegawa S: Heme oxygenase 1 is required for mammalian iron reutilization. Proc Natl Acad Sci USA 94: 10919-10924, 1997. 